\title{
First Clinical Evidence That Imaging with Somatostatin Receptor Antagonists Is Feasible
}

\author{
Damian Wild ${ }^{1}$, Melpomeni Fani ${ }^{1}$, Martin Behe ${ }^{1}$, Ingo Brink ${ }^{2}$, Jean E.F. Rivier ${ }^{3}$, Jean Claude Reubi ${ }^{4}$, Helmut R. Maecke ${ }^{1}$, \\ and Wolfgang A. Weber ${ }^{1}$ \\ ${ }^{1}$ Department of Nuclear Medicine, University Hospital Freiburg, Freiburg, Germany; ${ }^{2}$ Ernst von Bergmann Clinic, Potsdam, \\ Germany; ${ }^{3}$ Clayton Foundation Laboratories for Peptide Biology, Salk Institute, La Jolla, California; and ${ }^{4}$ Division of Cell \\ Biology and Experimental Cancer Research, Institute of Pathology, University of Berne, Berne, Switzerland
}

\begin{abstract}
Preclinical studies have indicated that somatostatin receptor (sst)-expressing tumors demonstrate higher uptake of radiolabeled sst antagonists than of sst agonists. In this study, we evaluated whether imaging with sst antagonists was feasible in patients. Methods: Biodistribution and tumor uptake of the sst antagonist ${ }^{111}$ In-DOTA-pNO ${ }_{2}$-Phe-c(DCys-Tyr-DTrp-Lys-ThrCys)DTyrNH ${ }_{2}$ ( ${ }^{111}$ In-DOTA-BASS) were studied in 5 patients with metastatic thyroid carcinoma or neuroendocrine tumors. Findings were compared with ${ }^{111} \mathrm{In}$-pentetreotid $\left({ }^{111} \mathrm{In}\right.$-DTPA-octreotide) scan. Results: No adverse effects of ${ }^{111}$ In-DOTA-BASS (20 $\mu \mathrm{g})$ were observed. ${ }^{111}$ In-DOTA-BASS detected 25 of 28 lesions, whereas ${ }^{111}$ In-DTPA-octreotide detected only 17 of 28 lesions. In the same patient, ${ }^{111} \mathrm{In}$-DOTA-BASS showed higher tumor and lower renal uptake than ${ }^{111}$ In-DTPA-octreotide $(3.5 \pm 2.8$ percentage injected activity $[\% \mathrm{IA}]$ vs. $1.0 \pm 0.99 \% \mathrm{IA}$ and $1.5 \pm 0.3 \% \mathrm{IA}$ vs. $2.3 \pm 0.7 \% \mathrm{IA})$ at $4 \mathrm{~h}$ after injection. Conclusion: Imaging of neuroendocrine tumors with sst antagonists is clinically feasible. The favorable human biodistribution data suggest that sst antagonists could significantly affect peptide receptor-mediated imaging and therapy.
\end{abstract}

Key Words: somatostatin receptor targeting; neuroendocrine tumors; somatostatin receptor antagonists; antagonists

J Nucl Med 2011; 52:1412-1417

DOI: 10.2967/jnumed.111.088922

\section{$\mathbf{T}$} argeting of G-protein-coupled receptors with radiolabeled receptor agonists is a promising diagnostic and therapeutic approach in oncology (1). Radiolabeled somatostatin receptor (sst) agonists have become an integral part of diagnostic and therapeutic management of patients with neuroendocrine tumors (2,3). Although agonists readily internalize into tumor cells, permitting accumulation of radioactivity, radiolabeled antagonists do not and have therefore not been used clinically for tumor targeting.

Received Feb. 7, 2011; revision accepted May 20, 2011.

For correspondence or reprints contact: Damian Wild, Department of Nuclear Medicine, University Hospital Freiburg, Hugstetterstrasse 55, D-79106 Freiburg, Germany.

E-mail: damian.wild@uniklinik-freiburg.de

Published online Aug. 18, 2011.

COPYRIGHT @ 2011 by the Society of Nuclear Medicine, Inc.
Ginj et al., however, showed in animal studies that radiolabeled sst antagonists are superior to agonists for the in vivo targeting of tumors expressing sst subtypes $2\left(\mathrm{sst}_{2}\right)$ and $3\left(\mathrm{sst}_{3}\right)(4)$. The in vivo uptake in $\mathrm{sst}_{2}$-positive tumors was twice as high with the antagonist ${ }^{111} \mathrm{In}-\mathrm{DOTA}-\mathrm{pNO}_{2}$ Phe-c(DCys-Tyr-DTrp-Lys-Thr-Cys)DTyrNH 2 ( ${ }^{111}$ In-DOTABASS) as with the highly potent agonist $\left[{ }^{111}\right.$ In-DTPA $^{0}$, $\mathrm{Tyr}^{3}, \mathrm{Thr}^{8}$ ]-octreotide $\left({ }^{111}\right.$ In-DTPA-TATE) (DTPA is diethylenetriaminepentaacetic acid). Scatchard analysis in human embryonic kidney (HEK)-sst ${ }_{2}$ cells showed more than 10 times the number of binding sites for ${ }^{111}$ In-DOTA-BASS (maximum number of $\mathrm{sst}_{2}$ binding sites, $354 \pm 14 \mathrm{pM}$ ) as for ${ }^{111} \mathrm{In}$-DTPA-TATE (maximum number of $\mathrm{sst}_{2}$ binding sites, $23 \pm 1.0 \mathrm{pM}$ ) (4). The same observation has been made for $5-\mathrm{HT}_{2 \mathrm{~A}}$ receptors and corticotrophin-releasing factor receptors $(5,6)$. Comparison of radiolabeled agonists and antagonists in a gastrin-releasing peptide receptor-positive prostate cancer animal model also showed the superiority of antagonists in an additional receptor system $(7,8)$. If confirmed clinically, these observations could lead to a paradigm shift in the development of radiolabeled G-protein-coupled receptor ligands for diagnostic and therapeutic purposes.

The purpose of this pilot study was to evaluate the feasibility of imaging sst-expressing tumors in patients with the novel receptor antagonist ${ }^{111}$ In-DOTA-BASS. Tumor detection rate and tracer uptake by tumors and normal organs were determined at various times and compared with recent ${ }^{111}$ In-DTPA-octreotide scans. On the basis of the biodistribution of ${ }^{111}$ In-DOTA-BASS, estimates were made for the expected radiation dosimetry of the therapeutic radioligand ${ }^{90} \mathrm{Y}$-DOTA-BASS.

\section{MATERIALS AND METHODS}

\section{Patients}

Five consecutive patients with progressive disease after standard therapy were prospectively recruited. Their tumors demonstrated low or moderate uptake of ${ }^{111}$ In-DTPA-octreotide (tumor uptake less than or slightly above liver uptake) limiting the efficacy of radionuclide therapy with sst agonists. Patient characteristics are summarized in Table 1. Exclusion criteria were renal insufficiency, treatment with short-acting somatostatin analogs less than $3 \mathrm{~d}$, and sandostatin depot injection less than $4 \mathrm{wk}$ before scanning. The use 
TABLE 1

Patient Characteristics

\begin{tabular}{lcccc}
\hline Patient no. & Age $(\mathrm{y})$ & Sex & Tumor type & Previous treatment $^{\star}$ \\
\hline 1 & 59 & $\mathrm{M}$ & Follicular thyroid cancer & Isotretinoin redifferentiation therapy \\
2 & 66 & $\mathrm{M}$ & Neuroendocrine tumor & 90Y-DOTATOC therapy \\
3 & 60 & $\mathrm{M}$ & Neuroendocrine tumor & Sandostatin therapy \\
4 & 56 & $\mathrm{M}$ & Neuroendocrine tumor & Transabdominal chemoembolization \\
5 & 74 & $\mathrm{M}$ & Neuroendocrine tumor & Hemihepatectomy \\
& & & \\
& & &
\end{tabular}

of ${ }^{111}$ In-DOTA-BASS in this setting was approved by the local institutional review board, and written informed consent was obtained in accordance with the Declaration of Helsinki.

\section{Radiochemistry}

The peptide-chelator conjugate DOTA- $\mathrm{pNO}_{2}$-Phe-c(DCys-TyrDTrp-Lys-Thr-Cys)DTyrNH $\mathrm{H}_{2}$ (DOTA-BASS) (Fig. 1) was synthesized under good manufacturing practice conditions by standard 9-fluorenylmethoxycarbonyl solid-phase synthesis as previously described (9). The pure compound was characterized by electrospray ionization mass spectrometry and analytic reversed-phase high-performance liquid chromatography.

For the preparation of ${ }^{111} \mathrm{In}-\mathrm{DOTA}-\mathrm{BASS}, 500 \mu \mathrm{L}$ of ammonium acetate buffer $(0.4 \mathrm{M}, \mathrm{pH} 5.0)$ were added to the vial containing $25 \mu \mathrm{g}$ of DOTA-BASS and incubated with approximately $200 \mathrm{MBq}$ of ${ }^{111} \mathrm{InCl}_{3}$ (Mallinckrodt) for $30 \mathrm{~min}$ at $95^{\circ} \mathrm{C}$. Quality control of the final product was performed by analytic reversedphase high-performance liquid chromatography and instant thinlayer chromatography. ${ }^{111}$ In-DTPA-octreotide was prepared with the commercially available kit Octreoscan (Covidien). The labeling yield of ${ }^{111}$ In-DOTA-BASS and ${ }^{111}$ In-DTPA-octreotide was $95 \%$ or greater at a specific activity of $12 \mathrm{GBq} / \mu \mathrm{mol}$ and 26 $\mathrm{GBq} / \mu \mathrm{mol}$, respectively. The radiochemical purity of ${ }^{111} \mathrm{In}-$ DOTA-BASS was greater than $95 \%$.

\section{Imaging}

Total-body and SPECT ${ }^{111}$ In-DOTA-BASS scans were obtained 11-13 d after ${ }^{111}$ In-DTPA-octreotide scans. All studies were done with the same dual-head $\gamma$-camera (Skylight; Phillips) equipped with medium-energy, parallel-hole collimators. ${ }^{111}$ In-DTPAoctreotide planar scans were obtained at 4 and $24 \mathrm{~h}$ after injection of approximately $10 \mu \mathrm{g}(167-192 \mathrm{MBq})$ of ${ }^{111} \mathrm{In}-$ DTPA-octreotide (European Association of Nuclear Medicine guidelines (10)), and sst antagonist total-body scans were obtained at $0.5,1,4,24,48$, and $72 \mathrm{~h}$ after injection of $20 \mu \mathrm{g}$ (145-176 MBq) of ${ }^{111}$ In-DOTA-BASS. For both tracers, SPECT images of the abdomen and thorax were acquired at $5 \mathrm{~h}$ after injection $\left(2 \times 180^{\circ}\right.$ rotation; 64 projections; $128 \times$ 128 matrix; 30-s acquisition time per projection). Patients' vital parameters such as blood pressure, pulse rate, oxygen saturation, and electrocardiogram were monitored for at least $2 \mathrm{~h}$ after injection of ${ }^{111}$ In-DOTA-BASS.

${ }^{111}$ In-DOTA-BASS and ${ }^{111}$ In-DTPA-octreotide scans were assessed independently by 2 experienced nuclear medicine physicians. The physicians were unaware of patients' identity, type of scan, and results of other imaging modalities. Afterward, the image findings were compared lesion by lesion with each other and with contrast-enhanced CT studies of the chest and abdomen. These scans had been acquired less than 5 wk before the ${ }^{111}$ InDTPA-octreotide scans using various multislice CT scanners.

\section{Pharmacokinetics}

For all imaging time points, regions of interest were manually drawn around the whole body and each organ with visible uptake (kidneys, spleen, liver, bladder, and tumor lesions), on both the anterior and the posterior scans. Background regions were placed close to the regions of interest for background correction. The geometric mean value, between anterior and posterior, was taken and corrected for attenuation using the conjugate-view method (11). Whole-body activity acquired $30 \mathrm{~min}$ after injection of ${ }^{111} \mathrm{In}$ DOTA-BASS was set as 100 percentage injected activity (\%IA).<smiles>C[C@H](O)C(NC(=O)[C@H](CCCCN)NC(=O)[C@H](Cc1c[nH]c2ccccc12)NC(=O)[C@H](Cc1ccc(O)cc1)NC(=O)[C@H](CSSC[C@H](NC(=O)[C@H](Cc1ccc([N+](=O)[O-])cc1)NC(=O)CN1CCN(CC(=O)O)CCN1CCC(=O)O)C(=O)N[C@@H](Cc1ccc(O)cc1)C(N)=O)NCC(=O)O)C(N)=O</smiles>

FIGURE 1. Structural formula of sst antagonist DOTA-BASS. 


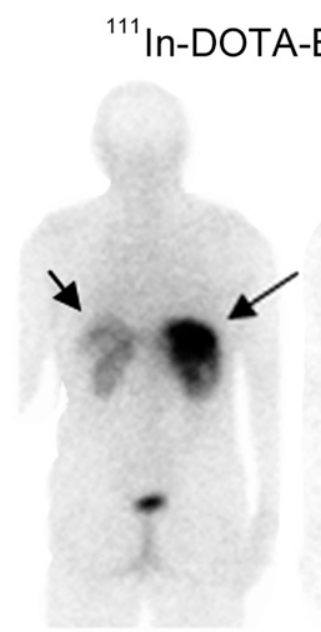

4 h p.i.

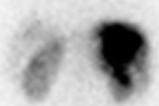

24 h p.i.

72 h p.i.

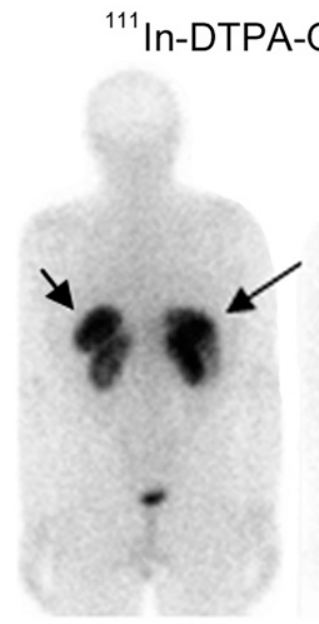

$4 \mathrm{~h}$ p.i.

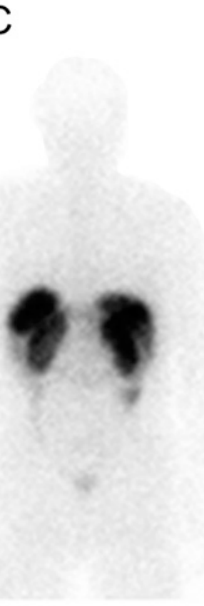

24 h p.i.

FIGURE 2. ${ }^{111} \mathrm{In}$-DOTA-BASS $(4,24$, and $72 \mathrm{~h}$ after injection) and ${ }^{111}$ In-DTPA-octreotide (4 and $24 \mathrm{~h}$ after injection) planar posterior whole-body scans from patient 4 . Large arrow shows increased uptake of ${ }^{111} \mathrm{In}$-DOTA-BASS and ${ }^{111} \mathrm{In}$-DTPA-octreotide in liver, corresponding to multiple liver metastases. Tumor-to-kidney uptake ratio was several times higher for ${ }^{111} \mathrm{In}$-DOTA-BASS $(6.1$ at $4 \mathrm{~h}$ after injection and 3.3 at $24 \mathrm{~h}$ after injection) than for ${ }^{111} \mathrm{In}$-DTPA-octreotide (1.18 at $4 \mathrm{~h}$ after injection and 0.88 at $24 \mathrm{~h}$ after injection). Small arrow shows spleen. $\mathrm{OC}=$ octreotide; p.i. = after injection.

Blood samples were taken at 1, 2, 3, 4, 5, 10, 20, 30, and 60 min and $1.5,4$, and $24 \mathrm{~h}$ after injection.

\section{Dosimetry}

Time-activity curves derived from the whole-body studies were analyzed with the OLINDA/EXM 1.0 software (Vanderbilt University) (12) to calculate the radiation dose after administration of ${ }^{111}$ In-DOTA-BASS. For the latter calculation, it was assumed that ${ }^{111}$ In-DOTA-BASS and ${ }^{90}$ Y-DOTA-BASS demonstrate an identical biodistribution. Organ doses were calculated for the wholebody male phantom. Blood marrow doses were determined by the blood-based red marrow dose methodology, which assumes a linear relation between the blood residence time and the red marrow residence time (13).

\section{RESULTS}

\section{Pharmacokinetics and Dosimetry}

None of the patients experienced adverse reactions after intravenous injection of $20 \mu \mathrm{g}$ of ${ }^{111} \mathrm{In}$-DOTA-BASS. Blood sampling revealed a biexponential blood clearance of ${ }^{111} \mathrm{In}$-DOTA-BASS: $\alpha$-half-life, $12.5 \pm 1.9 \mathrm{~min}$ and $\beta$-half-life, $6.1 \pm 1.1 \mathrm{~h}$; approximately $65 \%$ of the administered activity was cleared in the $\alpha$-phase. The clearance occurred predominantly via the kidneys. The longest residence times of ${ }^{111}$ In-DOTA-BASS were observed in the tumor and kidneys (Figs. 2 and 3).

\section{${ }^{111}$ In-DOTA-BASS}

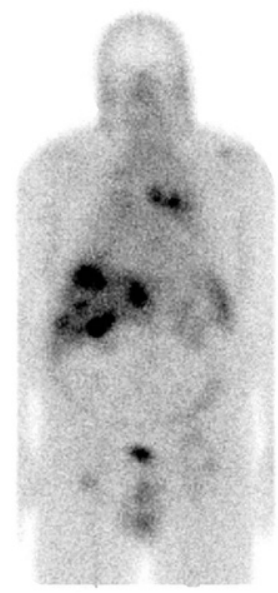

$4 \mathrm{~h}$ p.i.

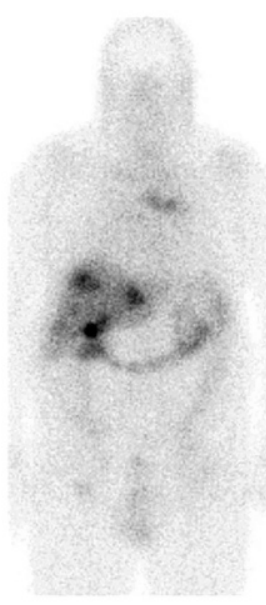

24 h p.i.

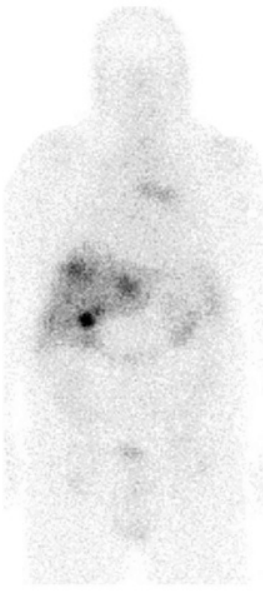

72 h p.i.

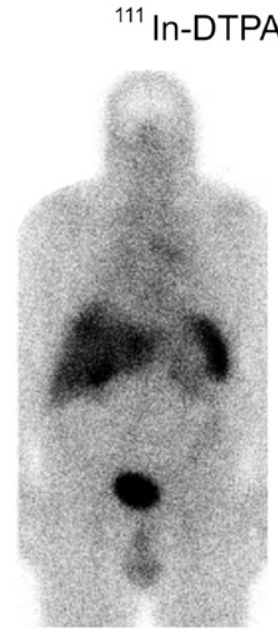

$4 \mathrm{~h}$ p.i.

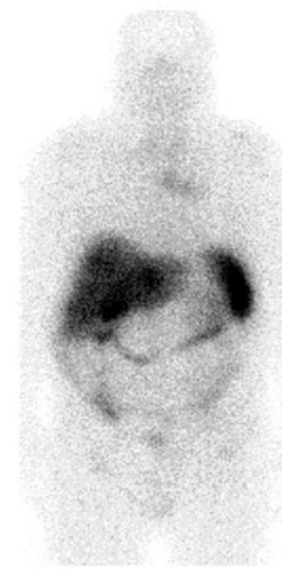

24 h p.i.
FIGURE 3. ${ }^{111} \mathrm{In}$-DOTA-BASS $(4,24$, and $72 \mathrm{~h}$ after injection) and ${ }^{111} \mathrm{In}$-DTPA-octreotide (4 and $24 \mathrm{~h}$ after injection) planar anterior whole-body scans from patient 2. Images illustrate better tumorto-background uptake ratio of ${ }^{111} \mathrm{In}$-DOTA-BASS (e.g., tumor-toliver uptake ratio of 6.7 at $4 \mathrm{~h}$ after injection and 3.5 at $24 \mathrm{~h}$ after injection) than of ${ }^{111}$ In-DTPA-octreotide (1.2 at both time points). In this patient, ${ }^{111} \mathrm{In}$-DOTA-BASS detected 16 metastases, whereas ${ }^{111}$ In-DTPA-octreotide detected only 11 metastases. OC $=$ octreotide; p.i. = after injection. 


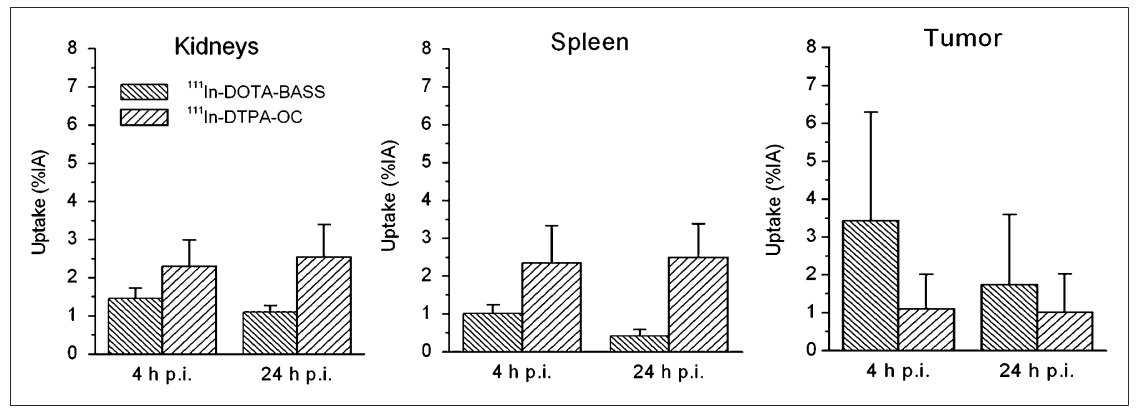

FIGURE 4. Comparison of ${ }^{111}$ In-DOTABASS and ${ }^{111}$ In-DTPA-octreotide uptake in kidneys, spleen, and tumors. Values are expressed as mean \pm SD of 5 patients. $\mathrm{OC}=$ octreotide; p.i. $=$ after injection.
In the quantitative analysis, there were relevant differences in the biodistribution between the sst antagonist ${ }^{111}$ In-DOTA-BASS and sst agonist ${ }^{111}$ In-DTPA-octreotide (Fig. 4). The antagonist showed up to 4.1 times higher uptake in the tumor ${ }^{111} \mathrm{In}-\mathrm{DOTA}-\mathrm{BASS}, 3.5 \pm 2.8 \% \mathrm{IA}$, and ${ }^{111}$ In-DTPA-octreotide, $1.0 \pm 0.99 \%$ IA) $4 \mathrm{~h}$ after injection. At the same time, the uptake in the kidneys was lower $\left({ }^{111}\right.$ In-DOTA-BASS, $1.5 \pm 0.3 \% \mathrm{IA}$, and ${ }^{111}$ In-DTPA-octreotide, $2.3 \pm 0.7 \%$ IA), resulting in up to 5.2 times higher tumor-to-kidney uptake ratio in favor of the antagonist (Supplemental Table 1 [supplemental materials are available online only at http://jnm.snmjournals. org]; Figs. 2 and 4). The antagonist also showed lower uptake in organs such as liver ( ${ }^{111}$ In-DOTA-BASS, $1.4 \pm$ $0.2 \% \mathrm{IA}$, and ${ }^{111} \mathrm{In}-\mathrm{DTPA}$-octreotide, $\left.1.7 \pm 0.6 \% \mathrm{IA}\right)$ and spleen $\left({ }^{111} \mathrm{In}\right.$-DOTA-BASS, $1.0 \pm 0.2 \% \mathrm{IA}$, and ${ }^{111} \mathrm{In}-$ DTPA-octreotide, $2.3 \pm 1.0 \% \mathrm{IA}) 4 \mathrm{~h}$ after injection.

The calculated effective radiation dose was $0.049 \pm$ $0.0076 \mathrm{mSv} / \mathrm{MBq}$ for ${ }^{111} \mathrm{In}-\mathrm{DOTA}-\mathrm{BASS}$ and $0.25 \pm$ $0.031 \mathrm{mSv} / \mathrm{MBq}$ for ${ }^{90} \mathrm{Y}-\mathrm{DOTA}-\mathrm{BASS}$ (Table 2). The crit-

TABLE 2

Absorbed Radiation Dose of ${ }^{111} \mathrm{In}-\mathrm{DOTA}-\mathrm{BASS}$ and ${ }^{90} \mathrm{Y}$-DOTA-BASS

\begin{tabular}{|c|c|c|c|}
\hline \multirow[b]{2}{*}{ Organ/tissue } & \multicolumn{2}{|c|}{ Wild et al., this study } & \multirow[b]{2}{*}{$\begin{array}{l}\text { Cremonesi et al. (17), } 90 \text { Y-DOTATOC } \\
\text { (mGy/MBq) }\end{array}$} \\
\hline & $\begin{array}{c}{ }^{111} \text { In-DOTA-BASS } \\
(\mathrm{mGy} / \mathrm{MBq})\end{array}$ & $\begin{array}{l}\text { 90Y-DOTA-BASS } \\
\text { (mGy/MBq) }\end{array}$ & \\
\hline Adrenals & $0.054 \pm 0.0092$ & $0.19 \pm 0.074$ & NA \\
\hline Brain & $0.031 \pm 0.0074$ & $0.19 \pm 0.074$ & NA \\
\hline Gallbladder wall & $0.053 \pm 0.0072$ & $0.19 \pm 0.074$ & NA \\
\hline \multicolumn{4}{|l|}{ Gastrointestinal tract } \\
\hline Lower large intestine wall & $0.049 \pm 0.010$ & $0.19 \pm 0.074$ & NA \\
\hline Small intestine & $0.049 \pm 0.010$ & $0.19 \pm 0.074$ & NA \\
\hline Stomach wall & $0.046 \pm 0.010$ & $0.19 \pm 0.074$ & NA \\
\hline Upper large intestine wall & $0.048 \pm 0.0098$ & $0.19 \pm 0.074$ & NA \\
\hline Heart wall & $0.043 \pm 0.0090$ & $0.19 \pm 0.074$ & $0.22 \pm 0.12$ \\
\hline Kidneys & $0.18 \pm 0.018$ & $1.92 \pm 0.21$ & $3.31 \pm 2.22$ \\
\hline Liver & $0.054 \pm 0.0078$ & $0.26 \pm 0.098$ & $0.72 \pm 0.57$ \\
\hline Lungs & $0.038 \pm 0.0078$ & $0.19 \pm 0.074$ & $0.31 \pm 0.18$ \\
\hline Muscle & $0.036 \pm 0.0077$ & $0.19 \pm 0.074$ & NA \\
\hline Pancreas & $0.057 \pm 0.011$ & $0.21 \pm 0.068$ & NA \\
\hline Red marrow & $0.041 \pm 0.0076$ & $0.18 \pm 0.041$ & $0.03 \pm 0.01$ \\
\hline Osteogenic cells & $0.086 \pm 0.019$ & $0.30 \pm 0.067$ & NA \\
\hline Skin & $0.024 \pm 0.0054$ & $0.16 \pm 0.042$ & NA \\
\hline Spleen & $0.12 \pm 0.034$ & $1.01 \pm 0.36$ & $7.62 \pm 6.30$ \\
\hline Thymus & $0.037 \pm 0.0087$ & $0.19 \pm 0.074$ & NA \\
\hline Thyroid & $0.037 \pm 0.0089$ & $0.19 \pm 0.074$ & NA \\
\hline Urinary bladder wall & $0.12 \pm 0.028$ & $0.98 \pm 0.36$ & $2.21 \pm 0.31$ \\
\hline Total body & $0.039 \pm 0.0079$ & $0.22 \pm 0.086$ & $0.14 \pm 0.06$ \\
\hline Effective dose (mSv/MBq) & $0.049 \pm 0.0076$ & $0.25 \pm 0.031$ & NA \\
\hline \multicolumn{4}{|c|}{$\begin{array}{l}\text { Data are mean } \pm \text { SD. } \\
\text { NA }=\text { not applicable. } \\
\text { Organ receiving highest dose was kidney. For therapeutic approach, it is likely that internalization and intracellular accumulation of } \\
\text { iort-range radionuclides (e.g., Auger emitters such as }{ }^{111} \mathrm{In} \text { ) is necessary because intracellular structures, for example, nucleus, are most } \\
\text { diosensitive part of cell. Because of cross-fire effect of medium- and long-range radionuclides (all } \beta \text { - and most } \alpha \text {-emitters), internal- } \\
\text { ation of such radionuclides is less likely to be relevant. }\end{array}$} \\
\hline
\end{tabular}


ical normal organs receiving the highest radiation dose were kidneys, spleen, and urinary bladder wall.

\section{Detection of Tumor Lesions}

${ }^{111}$ In-DOTA-BASS, ${ }^{111}$ In-DTPA-octreotide, and CT scans detected a total of 28 lesions; 25 were positive with ${ }^{111}$ InDOTA-BASS and 17 with ${ }^{111}$ In-DTPA-octreotide (Supplemental Table 2). All lesions visible on ${ }^{111}$ In-DTPA-octreotide scans were also detected by ${ }^{111}$ In-DOTA-BASS, whereas there were 8 lesions on ${ }^{111}$ In-DOTA-BASS that were not visible on ${ }^{111}$ In-DTPA-octreotide. There were 3 bone lesions that were negative on both ${ }^{111}$ In-DOTA-BASS and ${ }^{111}$ InDTPA-octreotide scans, but bone metastases were confirmed by serial CT.

\section{DISCUSSION}

Our pilot study provides the first clinical evidence that radiolabeled sst antagonists not only detect sst $_{2}$-expressing neuroendocrine tumors but also may even be superior to sst agonists for imaging and therapy of neuroendocrine tumors. The studied receptor antagonist ${ }^{111}$ In-DOTA-BASS had a favorable biodistribution profile (higher tumor uptake and lower organ uptake) than the agonist ${ }^{111}$ In-DTPA-octreotide, resulting in a higher tumor detection rate. The higher tumor uptake of ${ }^{111}$ In-DOTA-BASS is consistent with preclinical studies that have indicated that ${ }^{111}$ In-DOTA-BASS can bind to a larger number of $\mathrm{sst}_{2}$ conformations than sst agonists (4). The slightly better receptor affinity of ${ }^{111} \mathrm{In}$ DOTA-BASS than of ${ }^{111}$ In-DTPA-octreotide (inhibitory concentration of $50 \%, 9.4 \pm 0.4 \mathrm{nM}(4)$ vs. $22 \pm 3.6 \mathrm{nM}$ (14)) may also have contributed to the higher tumor uptake of ${ }^{111}$ In-DOTA-BASS.

With respect to radionuclide therapy, it is particularly encouraging that tumor-to-kidney ratios were up to 5.2 times higher for the antagonist than for the agonist. The kidneys are the major dose-limiting organ in peptide receptor radionuclide therapy, especially for ${ }^{90}$ Y-labeled receptor agonists $(3,15)$. On one hand, the severalfold higher tumor-to-kidney uptake ratio could significantly improve the efficacy and toxicity profile of radionuclide therapy with ${ }^{90}$ Y-labeled sst ligands, especially in patients with moderate ${ }^{111}$ In-DTPA-octreotide-avid tumor tissue (e.g., our patient collective). On the other hand, sst antagonists may have a negative effect on tumor growth. In vivo studies in rats showed a dose-dependent release of growth hormone growth hormone $(\mathrm{GH})$ after injection of sst antagonists (16). The minimum effective dose necessary to achieve growth hormone release was $0.02 \mathrm{mg} / \mathrm{kg}(17.4$ $\mathrm{nmol} / \mathrm{kg}$ ). The GH-releasing effect lasted about $15 \mathrm{~min}$. It is therefore unlikely that 20-200 $\mu \mathrm{g}$ (14-140 $\mathrm{nmol})$ of DOTA-BASS have any effects on tumor growth. To further evaluate the potential of somatostatin receptor antagonists for radionuclide therapy, we estimated the organ doses of ${ }^{90}$ Y-DOTA-BASS. For these calculations, we assumed that ${ }^{90}$ Y-DOTA-BASS shows the same biodistribution as ${ }^{111}$ InDOTA-BASS. ${ }^{111}$ In has been used extensively as surrogate for the pure $\beta$-emitter ${ }^{90} \mathrm{Y}$ because it has similar coordination chemistry, a similar physical half-life, and a similar metabolic handling $(1,17)$. Compared with literature data for ${ }^{90} \mathrm{Y}-$ DOTATOC $(18,19),{ }^{90}$ Y-DOTA-BASS showed lower renal, hepatic, and splenic radiation doses (Table 2).

The lower renal and liver doses can be explained by a charge difference between the 2 compounds. Negatively charged compounds such as ${ }^{111}$ In-DTPA-octreotide show often higher renal and liver doses than neutral compounds such as ${ }^{111}$ In- or ${ }^{90}$ Y-DOTA-BASS (20). The reasons for the low splenic uptake of ${ }^{111}$ In-DOTA-BASS are currently not clear.

The following limitations of the study should be noted. We have chosen the only Food and Drug Administrationand European Medicines Agency-approved sst imaging agent ( ${ }^{111}$ In-DTPA-octreotide) for comparison with our sst $_{2}$ antagonist ${ }^{111}$ In-DOTA-BASS. Comparison with unlicensed second-generation sst analogs-for example, ${ }^{111} \mathrm{In}$ DOTATOC_-was not possible because of legal reasons. However, choosing ${ }^{111}$ In-DTPA-octreotide is feasible because ${ }^{111}$ In-DTPA-octreotide and ${ }^{111}$ In-DOTATOC show similar biodistribution in humans, without significantly different tumor and kidney uptake (21).

Only 5 patients were included in this pilot study because the aim of the study was to obtain first clinical data on the potential usefulness of imaging sst-positive tumors with sst antagonists and not to determine the sensitivity and specificity of ${ }^{111}$ In-DOTA-BASS SPECT in a specific population.

\section{CONCLUSION}

This is the first proof of concept showing that imaging of neuroendocrine tumors with sst antagonists is feasible in patients. As suggested by preclinical studies, ${ }^{111}$ In-DOTABASS provided a higher tumor uptake and better visualization of metastatic neuroendocrine tumors than ${ }^{111}$ In-DTPA-octreotide. We anticipate that the antagonist approach will have significant impact on peptide receptor-mediated imaging and therapy.

\section{DISCLOSURE STATEMENT}

The costs of publication of this article were defrayed in part by the payment of page charges. Therefore, and solely to indicate this fact, this article is hereby marked "advertisement" in accordance with 18 USC section 1734.

\section{ACKNOWLEDGMENTS}

We thank Ulrike Buchegger-Podbielski and Christof Rottenburger at the University Hospital Freiburg for their support of the patient studies. This work was supported by the Swiss National Science Foundation (320000-118333). No other potential conflict of interest relevant to this article was reported.

\section{REFERENCES}

1. Reubi JC, Maecke HR. Peptide-based probes for cancer imaging. J Nucl Med. 2008;49:1735-1738. 
2. Ramage JK, Davies AH, Ardill J, et al. Guidelines for the management of gastroenteropancreatic neuroendocrine (including carcinoid) tumours. Gut. 2005; 54(suppl 4):iv1-iv16.

3. van Essen M, Krenning EP, Kam BL, de Jong M, Valkema R, Kwekkeboom DJ. Peptide-receptor radionuclide therapy for endocrine tumors. Nat Rev Endocrinol. 2009;5:382-393.

4. Ginj M, Zhang H, Waser B, et al. Radiolabeled somatostatin receptor antagonists are preferable to agonists for in vivo peptide receptor targeting of tumors. Proc Natl Acad Sci USA. 2006;103:16436-16441.

5. Sleight AJ, Stam NJ, Mutel V, Vanderheyden PM. Radiolabelling of the human 5- $\mathrm{HT}_{2 \mathrm{~A}}$ receptor with an agonist, a partial agonist and an antagonist: effects on apparent agonist affinities. Biochem Pharmacol. 1996;51:71-76.

6. Perrin MH, Sutton SW, Cervini LA, Rivier JE, Vale WW. Comparison of an agonist, urocortin, and an antagonist, astressin, as radioligands for characterization of corticotropin-releasing factor receptors. J Pharmacol Exp Ther. 1999; 288:729-734.

7. Cescato R, Maina T, Nock B, et al. Bombesin receptor antagonists may be preferable to agonists for tumor targeting. J Nucl Med. 2008;49:318-326.

8. Mansi R, Wang X, Forrer F, et al. Evaluation of a 1,4,7,10-tetraazacyclododecane-1,4,7,10-tetraacetic acid-conjugated bombesin-based radioantagonist for the labeling with single-photon emission computed tomography, positron emission tomography, and therapeutic radionuclides. Clin Cancer Res. 2009;15: 5240-5249.

9. Altherton E, Sheppard R. Fluorenylmethoxycarbonyl-Polyamide Solid Phase Peptide Synthesis. General Principles and Development. Oxford, U.K.: Oxford Information Press; 1989.

10. Bombardieri E, Ambrosini V, Aktolun C, et al. 111In-pentetreotide scintigraphy: procedure guidelines for tumour imaging. Eur J Nucl Med Mol Imaging. 2010;37: 1441-1448.

11. Siegel JA, Thomas SR, Stubbs JB, et al. MIRD pamphlet no. 16: techniques for quantitative radiopharmaceutical biodistribution data acquisition and analysis for use in human radiation dose estimates. $J$ Nucl Med. 1999;40:37S-61S.
12. Stabin MG, Sparks RB, Crowe E. OLINDA/EXM: the second-generation personal computer software for internal dose assessment in nuclear medicine. $\mathrm{J} \mathrm{Nucl}$ Med. 2005;46:1023-1027.

13. Sgouros G. Bone marrow dosimetry for radioimmunotherapy: theoretical considerations. J Nucl Med. 1993;34:689-694.

14. Reubi JC, Schar JC, Waser B, et al. Affinity profiles for human somatostatin receptor subtypes SST1-SST5 of somatostatin radiotracers selected for scintigraphic and radiotherapeutic use. Eur J Nucl Med. 2000;27:273-282.

15. Moll S, Nickeleit V, Mueller-Brand J, Brunner FP, Maecke HR, Mihatsch MJ. A new cause of renal thrombotic microangiopathy: ${ }^{90}$ Y-DOTATOC internal radiotherapy. Am J Kidney Dis. 2001;37:847-851.

16. Tulipano G, Soldi D, Bagnasco M, et al. Characterization of new selective somatostatin receptor subtype-2 ( $\left.\mathrm{sst}_{2}\right)$ antagonists, BIM-23627 and BIM23454. Effects of BIM-23627 on GH release in anesthetized male rats after short-term high-dose dexamethasone treatment. Endocrinology. 2002;143:12181224 .

17. Maecke HR, Riesen A, Ritter W. The molecular structure of indium-DTPA. J Nucl Med. 1989;30:1235-1239.

18. Cremonesi M, Ferrari M, Zoboli S, et al. Biokinetics and dosimetry in patients administered with ${ }^{111} \mathrm{In}$-DOTA-Tyr ${ }^{3}$-octreotide: implications for internal radiotherapy with ${ }^{90}$ Y-DOTATOC. Eur J Nucl Med. 1999;26:877-886.

19. Forrer F, Uusijarvi H, Waldherr C, et al. A comparison of ${ }^{111}$ In-DOTATOC and ${ }^{111}$ In-DOTATATE: biodistribution and dosimetry in the same patients with metastatic neuroendocrine tumours. Eur J Nucl Med Mol Imaging. 2004;31: 1257-1262.

20. Froidevaux S, Eberle AN, Christe M, et al. Neuroendocrine tumor targeting: study of novel gallium-labeled somatostatin radiopeptides in a rat pancreatic tumor model. Int J Cancer. 2002;98:930-937.

21. Kwekkeboom DJ, Kooij PP, Bakker WH, Macke HR, Krenning EP. Comparison of ${ }^{111} \mathrm{In}$-DOTA-Tyr ${ }^{3}$-octreotide and ${ }^{111} \mathrm{In}$-DTPA-octreotide in the same patients: biodistribution, kinetics, organ and tumor uptake. J Nucl Med. 1999; 40:762-767. 